On the ordinary steam temperature-entropy chart, $a g$ being the water line, the line $a b c$ divides the whole area fagce into external energy $E$ and internal energy $A+B$. The Rankine-Clausius cycle being $a g, g c, c d$, $d a$, its efficiency is $\frac{A+E}{A+B+E}$, and this is obviously greater than the Haldane cycle efficiency, since the area $E$ bears a greater proportion to the area $A$ than to the area $A+B$.

The Carnot cycle is simply $a h, h c, c d, d a$, and its efficiency is $\frac{A+E+D}{A+B+E+D}$, which, for a similar reason, is greater than $\frac{A+E}{A+B+E}$ for the Rankine-Clausius cycle.

As a numerical example, take I $\mathrm{lb}$. of water at a temperature of $140^{\circ} \mathrm{F}$. corresponding to $3 \mathrm{Ib}$. per sq. in. absolute back pressure, and let this be evaporated into steam at $34 \mathrm{I}^{\circ} \mathrm{F}$. corresponding to an absolute pressure of $120 \mathrm{lb}$. per sq. in.

From steam tables, the total heat in $\mathrm{r} \mathrm{lb}$. water at

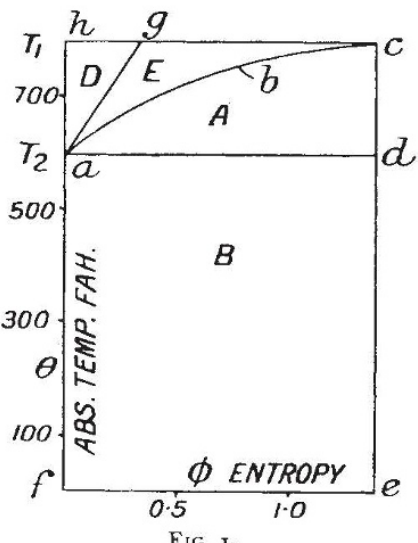

$34^{\circ} \mathrm{F}$. above $32^{\circ} \mathrm{F}$. is II 86 B.T.U., the external energy $E$ is $82 \cdot I$ B.T.U., and latent heat is 874 B.T.U. Hence

$A+B=\mathrm{II} 86-\left(\mathrm{x}_{4} \mathrm{O}-32\right)-82 \cdot \mathrm{I}=995 \cdot 9$ B.T.U.

To find area $B$, first calculate $a d$ or $\phi_{2}$.

$$
\phi_{2}=\log _{\epsilon}\left(\frac{34 I+460}{I 4 O+460}\right)+\frac{874}{34 I+460}=I \cdot 3803 .
$$

Thus

and

$$
\text { area } B=600 \times \mathrm{x} \cdot 3803=828 \cdot \mathrm{I} 8 \text { B.T.U. }
$$

$$
\text { area } A=995 \cdot 9-828 \cdot \mathbf{1} 8=\mathbf{1} 67 \cdot 7 \text { B.T.U. }
$$

The efficiency is therefore $\frac{I 67 \cdot 7}{995.9}=I 6.7$ per cent.

For the same data, the Rankine-Clausius efficiency is

$$
\frac{A+E}{A+B+E}=\frac{\mathbf{I} 67 \cdot 7+82 \cdot \mathbf{I}}{995 \cdot 9+82 \cdot \mathbf{I}}=23 \cdot \mathrm{I} \text { per cent., }
$$

and the Carnot efficiency

$$
=\frac{A+E+D}{A+B+E+D}=\frac{a h}{f h}=\frac{80 \mathrm{I}-600}{80 \mathrm{I}}=25 \text { per cent. }
$$

The chart is drawn approximately to scale for the above data. The higher efficiencies of the two lastnamed cycles are simply due to the addition of a large proportion of heat at the higher temperature. The Haldane cycle omits this and is therefore of lower efficiency.

H. W. HEATH.

H.M. Patent Office

25 Southampton Buildings,

Chancery Lane, W.C.2.

NO. 2927 , VOL. I I 6$]$

\section{The London Skull.}

IN his most interesting article on the London Skull, in NATURE of November 7, Prof. G. Elliot Smith states that " The deposit in which the human remains were found forms part of the third (or lowest) terrace of the Thames containing the characteristic late Pleistocene fauna . . . presumptive age [of the skull] must be assumed to be later than the Mousterian phase of culture."

On the Geological Survey Maps (one-inch sheet 256 North London; six-inch London $7 \mathrm{SE}$ ) the site is shown as Middle Terrace. In the memoirs dealing with the area it is stated that this terrace has yielded late Acheulian types of implements, and that from its surface, overwhelmed by Coombe Rock or Trail, numerous Mousterian implements have been found above, in, and below London. Moreover, the various mammals mentioned by Prof. Elliot Smith as occurring at the Leadenhall Street site are mentioned among those found in this terrace (" Geology of the London District," 2nd ed., r922, pp. 49-70 ; "Geology of North London," I925, pp. 4I-49).

If this view of the age of the deposits in which the skull was found is correct, its Neanderthal character, so far from suggesting " the possibility of the survival into Aurignacian times (in Britain) of a stray representative of the species neanderthalensis," is quite normal. Being responsible for the maps and memoirs alluded to, I should be glad to know on what grounds Prof. Elliot Smith assigns the deposit to the Low Terrace instead of the Middle, thereby involving himself in a difficulty as to the human species represented by his skull.

Geological Survey Office,

I 4A Parliament Street, York.

I AM very grateful to Mr. Bromehead for directing my attention to the evidence for identifying the London Terraces. In reply to his query on what grounds I assign the deposit at Lloyd's to the Low Terrace instead of the Middle, I can only say that I have never claimed any competence to decide the geological points at issue; but, as I have already stated in public and in print on several occasions, have taken the opinions expressed when the ulna of the woolly rhinoceros (from the same level in the blue clay at Lloyd's) was exhibited at a meeting of the Zoological Society last March.

The decision of the age of the deposit, concerning which several geologists have written to me, has become of such crucial importance that last week the matter was referred to Prof. Boswell for his advice.

I need scarcely say that if Mr. Bromehead's opinion (which in private correspondence Prof. Sollas and Mr. Reid Moir had already suggested to me) should prove correct, it will facilitate my task of interpretation. For the London skull conforms much more nearly to the Neanderthal type than to the form that is usual in Homo sapiens. The fulness of the cerebellum, however, is in sharp contrast with the flattened Neanderthal type. The cranium is as thin as that of a modern woman's. In this respect, however, it agrees with the Neanderthal cranium found in I9II at La Quina. Moreover, as Prof. Wingate Todd has pointed out (Anat. Record, vol. 27, I924, p. 245), thickness of skull is so variable a feature as to have no decisive value as a specific criterion. Hence the points of difference between the London skull and the Neanderthal type are not necessarily significant. So that, if the blue clay can be shown to 